\title{
Study on Water Splitting Potential of Some Metallurgical Wastes for Production of Hydrogen
}

\author{
Volodymyr Shatokha ${ }^{1} \cdot$ Iulia Sokur $^{1} \cdot$ Liudmyla Kamkina $^{1}$
}

Published online: 19 January 2016

(C) The Minerals, Metals \& Materials Society (TMS) 2016

\begin{abstract}
Development of reliable and cost-effective technologies to produce hydrogen is very important in the context of climate change mitigation. Even partial substitution of carbonaceous fuels and reductants in ironmaking may reduce $\mathrm{CO}_{2}$ emissions considerably. Hydrogen-based ironmaking technologies are being developed; however, their commercialization is constrained by availability and cost of hydrogen. Approaches such as solar hydrogen, fuel cells, and bio-hydrogen are being extensively studied worldwide; however, for the most part, these developments have uncertain potential to produce hydrogen for industrial applications in ironmaking owing to their complexity, insufficient productivity, and high cost. The potential of some widely available materials and wastes to be used as contact mass in the thermo-chemical water splitting processes for on-site production of hydrogen at a steel factory towards future hydrogen-based ironmaking is studied in the current paper by using thermodynamic modeling.
\end{abstract}

Keywords Thermochemical water splitting - Ferrous wastes $\cdot$ Hydrogen ironmaking

The contributing editor for this article was S. Kitamura.

Volodymyr Shatokha

shatokha@gmail.com; shatokha@metal.nmetau.edu.ua

1 National Metallurgical Academy of Ukraine, Dnipropetrovsk, Ukraine

\section{Introduction}

Hydrogen is the only fuel producing nothing but water as a combustion product and hence it is widely considered as the most promising green energy carrier [1]. Moreover, water is also the only gaseous product of iron ore reduction by hydrogen. Novel hydrogen-based ironmaking processes are being developed nowadays, such as flash ironmaking; however, the high cost of hydrogen is one of the barriers for commercialization of this technology [2]. Hence, use of hydrogen for metal smelting is considered by the Intergovernmental Panel for Climate Change (IPCC) as a longer-term option for mitigating the industrial $\mathrm{CO}_{2}$ emissions, capable of entering the marketplace only later than 2030 [3]. Therefore, development of a reliable and cost-effective technology to produce hydrogen is very important in the context of climate change mitigation. Not only the economically feasible production of hydrogen but also its transportation and storage in large quantities are noted among the challenges to overcome [4, 5]; consequently, on-site production of inexpensive hydrogen at a steelmaking enterprise can be considered as an important step for bringing about novel hydrogen-based ironmaking processes to an industrial scale.

One of the most attractive approaches to produce hydrogen is thermochemical water splitting by metal oxide, directly yielding hydrogen without a need to separate hydrogen and oxygen [6]:

$\mathrm{MeO}_{x}+\mathrm{H}_{2} \mathrm{O}=\mathrm{MeO}_{x+1}+\mathrm{H}_{2}$

The two-step water splitting process uses a redox system where reaction (1) is coupled with thermal decomposition producing the initial reactant

$\mathrm{MeO}_{x+1}=\mathrm{MeO}_{x}+1 / 2 \mathrm{O}_{2}$ 
Environmental friendliness of the approach is evident: oxygen is the only by-product. Application of solar energy for thermal decomposition (reaction 2) should be mentioned among the major directions of the ongoing research activities in the field. Among the problems the researchers encountered, the following can be mentioned [6-10]:

- High temperature for reaction (2) is observed for most of the oxides or mixed oxides (ferrites) studied so far, e.g., $2000{ }^{\circ} \mathrm{C}$ for $\mathrm{CeO}_{2} / \mathrm{Ce}_{2} \mathrm{O}_{3}$ cycle, $1900{ }^{\circ} \mathrm{C}$ for $\mathrm{Zn} /$ $\mathrm{ZnO}$ cycle, $2200{ }^{\circ} \mathrm{C}$ for $\mathrm{Fe}_{3} \mathrm{O}_{4} / \mathrm{FeO}$ cycle, $1800{ }^{\circ} \mathrm{C}$ for nickel manganese ferrite cycle, and $1800{ }^{\circ} \mathrm{C}$ for zinc manganese ferrite cycle;

- For the systems based on some materials other than oxides (sulfates, sodiums, chlorines, etc), thermal decomposition can occur at lower temperatures; however, it produces hazardous emissions (liquids and/or gases), thus making the process more complex;

- Very innovative and often expensive facilities (e.g., such as solar reactors) are needed;

- Poor durability of the materials used in the cycles.

The cycle based on the iron oxides is being studied by many researchers owing to the availability and comparatively low cost of materials. A two-step thermochemical cycle based on iron oxide redox pair $\mathrm{Fe}_{3} \mathrm{O}_{4} / \mathrm{FeO}$ for solar hydrogen production was investigated by Charvin et al. [8]. A high-temperature magnetite decomposition reaction was performed in a solar reactor set at the focus of a laboratoryscale solar furnace. A conversion of $83 \%$ was obtained for the hydrolysis reaction of non-stoichiometric solar wüstite $\mathrm{Fe}_{(1-y)} \mathrm{O}$ at $575^{\circ} \mathrm{C}$. It was also demonstrated that the rate of the initial phase of hydrolysis is limited by the kinetics of following chemical reaction

$3 \mathrm{FeO}+\mathrm{H}_{2} \mathrm{O}=\mathrm{Fe}_{3} \mathrm{O}_{4}+\mathrm{H}_{2}$

During the latter phases, the process is limited by diffusion of steam to the reaction front through the layer of reaction product (magnetite). A different course of the reaction was observed when commercial $\mathrm{Fe}_{x} \mathrm{O}_{y}$ was used instead of the one obtained by reducing hematite in a solar furnace which is explained by non-stoichiometry of the solar wüstite.

Water splitting reactions with wüstite and with iron manganese oxides were conducted by Ehrensberger et al. [9] exploring the possibility of using a material with a lower thermal decomposition temperature. Experimental results confirm the possibility to optimize the overall process via partial substitution of iron by another metal (e.g., such as manganese) forming mixed oxides with iron.

As an alternative to thermal decomposition, a reduction route has also been explored for the iron oxides cycle. Particularly, reduction of magnetite to iron in a reformer using synthesis gas (mixture of $\mathrm{H}_{2}, \mathrm{CO}, \mathrm{CO}_{2}$, and $\mathrm{H}_{2} \mathrm{O}$ gases obtained by catalytic conversion of hydrocarbons)

$\mathrm{Fe}_{3} \mathrm{O}_{4}+4 \mathrm{H}_{2}=3 \mathrm{Fe}+4 \mathrm{H}_{2} \mathrm{O}$

$\mathrm{Fe}_{3} \mathrm{O}_{4}+4 \mathrm{CO}=3 \mathrm{Fe}+4 \mathrm{CO}_{2}$

with a subsequent "sponge iron reaction process"

$3 \mathrm{Fe}+4 \mathrm{H}_{2} \mathrm{O}=\mathrm{Fe}_{3} \mathrm{O}_{4}+4 \mathrm{H}_{2}$

was studied by Thaler et al. [10]. It was found that the pellets made of pure iron oxides were quickly deactivated for redox reactions due to sintering effects. Addition of up to $6.5 \%$ of silica improves performance of the pellets by preventing sintering. The reformer sponge iron cycle (RESC) process has been validated at the laboratory scale. Possibility to use coal instead of natural gas for production of hydrogen for the sponge iron route was also studied [11]. It should be noted that although the quantity of the hydrogen produced in reaction (6) is the same as the one consumed in reaction (4), it is essential that reaction (6) yields pure hydrogen, whereas hydrogen in the reaction (4) is a component of a relatively cheap synthesis gas mixture, and hence the overall process might be feasible. Obviously, the reduction route is unsuitable for producing hydrogen for ironmaking: reduced iron is produced by reactions with syngas (4-5) and there is no reason to oxidize it again.

In the paper by Bleeker et al. [12], a possibility to produce pure hydrogen in the steam-iron process with application of pyrolysis oil gasification products as a reductant in a fluidized bed reactor was studied with two options: (1) a once-through concept, in which cheap iron oxide (sintered pellets of natural iron ore) is used in one cycle, before further processing in a blast furnace, and (2) a continuous system, in which specially developed iron oxides are cycled between a reduction and oxidation reactor. Deactivation of iron oxides has been observed by a decrease in reduction rate in subsequent redox cycles, explained by a decrease in the surface area.

Generally, it is possible to summarize that iron oxides are identified among the optimum materials to produce hydrogen by water splitting owing to combination of favorable thermodynamic properties, reaction rate, as well as their stability at high temperatures, availability, and cost. Various advanced processes to produce hydrogen are being developed; however, their technological feasibility has not been proven so far-especially in the volumes relevant to the needs of hydrogen ironmaking.

Even partial substitution of carbon reductants by hydrogen may reduce $\mathrm{CO}_{2}$ emissions considerably. Taking into account that production of $1 \mathrm{t}$ of steel via the integrated route is followed by emission of $1.8 \mathrm{t}$ of carbon dioxide on the average, with current level of steel 
production worldwide (if we take the share of steel produced via the integrated route as $60 \%$ ), substitution of even $10 \%$ of carbonaceous fuel by hydrogen will result in cutting the $\mathrm{CO}_{2}$ emissions by over 120 million tons per year.

It's noteworthy that thermodynamics of equilibrium in the system of $\mathrm{Fe}_{1-y} \mathrm{O}-\mathrm{Fe}_{3} \mathrm{O}_{4}-\mathrm{H}_{2}-\mathrm{H}_{2} \mathrm{O}$ were thoroughly studied 50 years ago by the researchers in the metallurgical domain, especially in the ironmaking context, and results were summarized very well by Bogdandy and Engel [13]. However, nowadays the metallurgical science and technology are underrepresented in the multidisciplinary efforts needed to bring about the water splitting technology capable of producing hydrogen for ironmaking.

Comparative cost analyses for hydrogen production technologies, especially those on the R\&D stage, are constrained by the lack of data publicly available. In the paper by T-Raissi and Block [14], it was stated that the cost to produce hydrogen by thermochemical water splitting (early R\&D stage) is generally six times more expensive compared to steam methane technology (mature technology). However, technological advancement of thermochemical water splitting including that one achieved by application of inexpensive raw materials may enhance its feasibility. The current paper explores the potential of some inexpensive metallurgical materials and wastes to produce hydrogen via the thermochemical water splitting processes.

\section{Materials and Methods}

Iron monoxide as a material with considerable potential for thermochemical water splitting is the focus of many researchers; however, it is a component of some widely available metallurgical products or even wastes. Data on $\mathrm{FeO}$ content in various materials are shown in Table 1. These materials have significant potential for water splitting due to the essential presence of $\mathrm{FeO}$ and they are available at integrated steel factories in large quantities. For example, the losses of metal in the form of rolling mills scale can reach up to $5 \%$ of the rolled product weight,

Table $1 \mathrm{FeO}$ content in various metallurgical materials

\begin{tabular}{ll}
\hline Material & FeO content, mass\% \\
\hline $\begin{array}{l}\text { Products } \\
\text { Iron ore sinter }\end{array}$ & $5-40$, depends upon technology \\
Wastes or by-products & \\
Rolling mills scale & Over 60 \\
Mill cinder & Up to 60 \\
Blast furnace dust & Up to 30 \\
Steelmaking slag & Up to 30 \\
\hline
\end{tabular}

steelmaking slag yield is $100-150 \mathrm{~kg}$ per one tonne, and the yield of blast furnace dust depends upon quality of raw materials and varies from 10 to $50 \mathrm{~kg}$ per tonne of hot metal produced.

Other waste materials with the potential for hydrogen production considered in this paper are ferrosilicon slag and wastes from aluminum production. Depending upon the alloy grade produced, ferrosilicon slag composition varies as follows (mass\%): 30-50 $\mathrm{SiO}_{2}, 10-25 \mathrm{Al}_{2} \mathrm{O}_{3}$, 8-15 CaO, 2-5 MgO, $10-20 \mathrm{SiC}$, and $15-30 \mathrm{Si}+$ $10-34 \mathrm{Fe}$. The slag yield is about $7 \%$ of the produced alloy and it is widely available in many countries producing ferrosilicon. Currently, most of the slag is dumped (it is used in foundries in minor quantities; attempts to use it in blast furnaces to produce high-Si iron are also known) [15].

To calculate thermodynamic parameters and to model phase equilibria, the HSC Chemistry 4.0 [16] and the Factsage 6.0 [17] software was used.

\section{Results and Discussion}

\section{Ferrous Wastes of Integrated Steelmaking Factories}

A possibility to generate hydrogen by reaction between $\mathrm{FeO}$ in molten steelmaking slag and water vapor was confirmed by Matsuura and Tsukihashi [18]. It was shown that in a molten slag this process is controlled by the reaction:

$2 \mathrm{FeO}+\mathrm{H}_{2} \mathrm{O}=\mathrm{Fe}_{2} \mathrm{O}_{3}+\mathrm{H}_{2}$

the Gibbs free energy of which $\left(\Delta G^{\circ}=-82,130+\right.$ $102.7 \mathrm{~T} \mathrm{~J} / \mathrm{mol}$ [19]) is positive above $800{ }^{\circ} \mathrm{C}$. Therefore, under the temperature conditions of molten slag this reaction cannot proceed spontaneously without external inputs. In our paper we study reactions of steelmaking slag with water vapor at moderated temperatures when the water splitting process is controlled by a thermodynamically favored reaction (3).

Depending upon the technology and raw materials used, steelmaking slag of a basic oxygen furnace (BOF) typically contains (mass\%) 40-60 CaO, 10-30 $\mathrm{SiO}_{2}, 15-30 \mathrm{FeO}$, 5-8 MnO, 4-8 MgO, and minor quantities of other components. In case it is used as a contact mass for water splitting, the reaction of water steam with calcium oxide, followed by the formation of calcium hydroxide (portlandite), may hamper process efficiency. Figure 1 establishes the temperature margins for the reactions of $\mathrm{CaO}$ and $\mathrm{FeO}$ with water. From thermodynamics, an optimal temperature range for water splitting by steelmaking slag is from 532 to $714{ }^{\circ} \mathrm{C}$, where water splitting by $\mathrm{FeO}$ is possible while calcium hydroxide cannot be formed. Below $532{ }^{\circ} \mathrm{C}$, both $\mathrm{FeO}$ and $\mathrm{CaO}$ may react with water, though in 


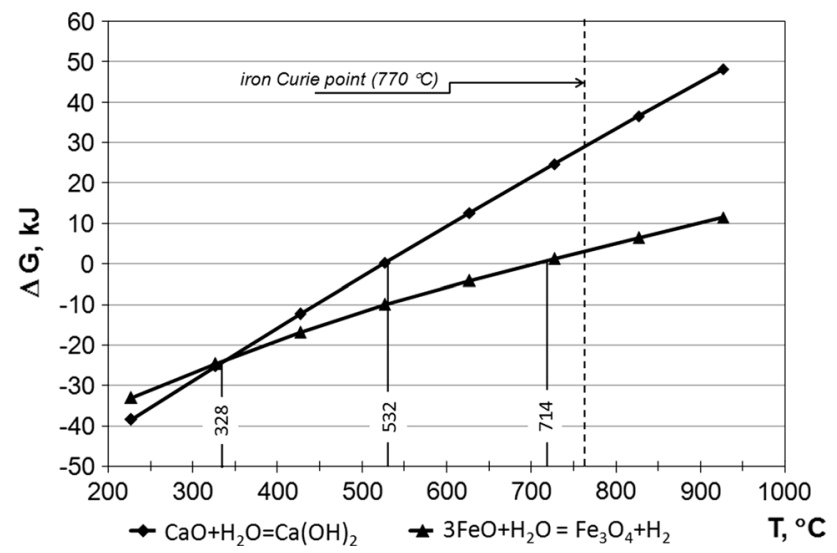

Fig. 1 Physicochemical conditions for water splitting by steelmaking slag

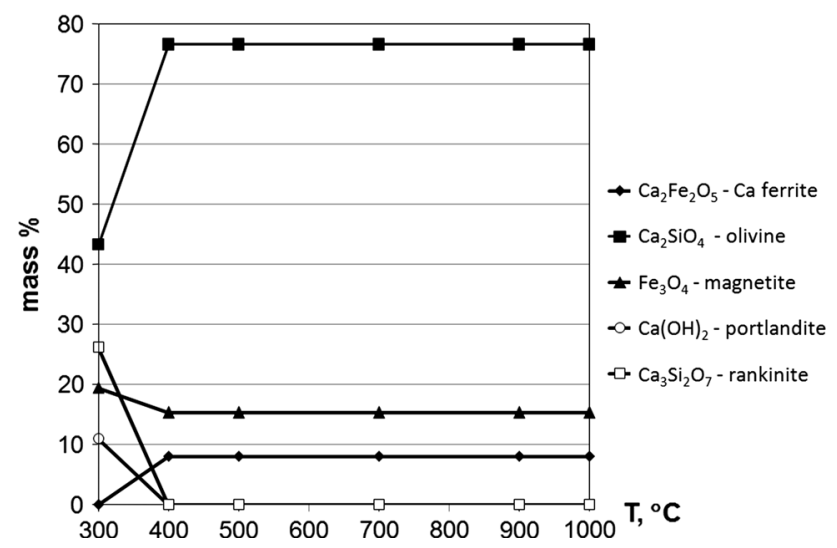

Fig. 2 Mass balance of hydrogen

the temperature range $328-532{ }^{\circ} \mathrm{C}$ a reaction with $\mathrm{FeO}$ thermodynamically is more favored. Below $328{ }^{\circ} \mathrm{C}$ forming of $\mathrm{Ca}(\mathrm{OH})_{2}$ is more favored thermodynamically than a reaction of water with $\mathrm{FeO}$.

To be processed in, e.g., a fluidized bed reactor or in another kind of apparatus in the abovementioned temperature range, slag must be cooled, solidified, and crushed. Steelmaking slag contains up to $8 \%$ of metallic iron [20], and it's reasonable to remove it for recycling before the slag is used for water splitting otherwise all iron will be oxidized. The abovementioned temperature range lies below the iron Curie point $\left(770{ }^{\circ} \mathrm{C}\right)$ and separation of metallic iron is possible without challenging water splitting reaction kinetics. However, a method to separate iron from the relatively hot slag must be developed in order to avoid its excessive cooling-i.e. below the threshold when portlandite is formed.

Even though the best temperature range revealed by Fig. 1 is relatively narrow, accurate process temperature control might be assisted by a slightly exothermal effect of the reaction (3) helping to compensate sensible heat losses.

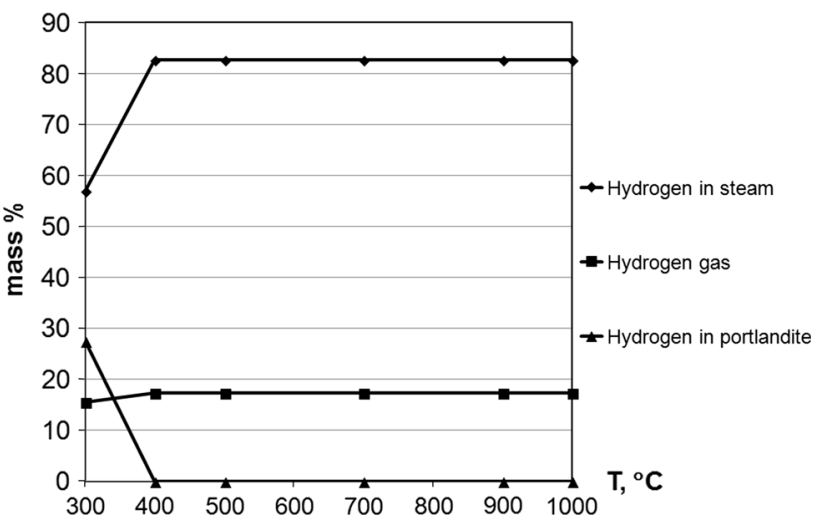

Fig. 3 Solid phase composition

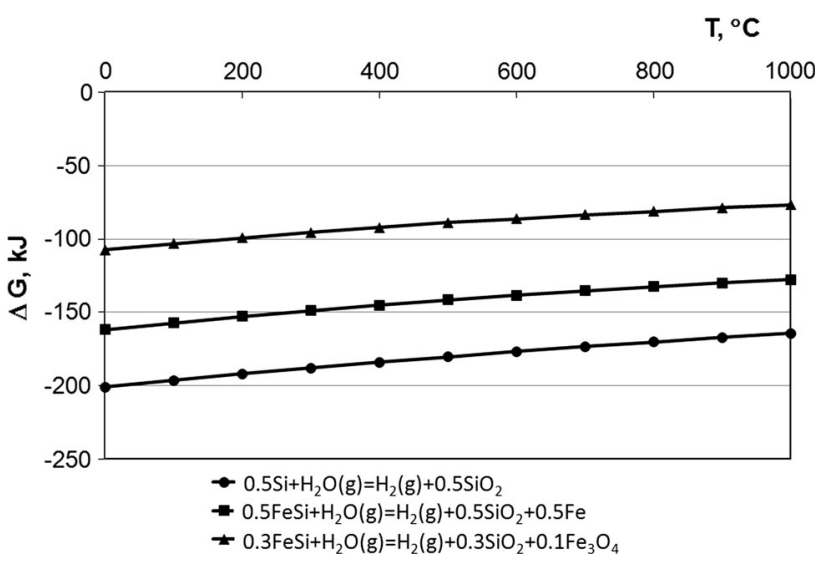

Fig. 4 Change of the Gibbs free energy versus temperature for the reactions, relevant to the system representing water splitting by ferrosilicon slag waste

In the work by Thaler et al. [10], a temperature in the layer of "metallized" pellets (hematite pellets were pre-reduced to iron and then oxidized by water to $\mathrm{Fe}_{3} \mathrm{O}_{4}$ ) is increased from 785 to $800{ }^{\circ} \mathrm{C}$ due to the reaction with water.

Magnetite Curie point is $585^{\circ} \mathrm{C}$; therefore magnetically susceptible $\mathrm{Fe}_{3} \mathrm{O}_{4}$ formed in reaction (3) can be easily separated from the slag after it is processed in water splitting. This is an additional argument to use slag in water splitting: separated magnetite-rich fraction might be used either in ironmaking or in other, more value-added, applications.

To estimate the interaction processes between steelmaking slag and water steam, the modeling with application of Factsage software was performed. The system representing slag composed of (mass\%) $54 \mathrm{CaO}, 27 \mathrm{SiO}_{2}$, and $19 \mathrm{FeO}$ and water in relation 100/10 (slag/water) was studied under atmospheric pressure in the temperature range from 300 to $1000{ }^{\circ} \mathrm{C}$. Mass balance of hydrogen, presented in Fig. 2, shows that above $400{ }^{\circ} \mathrm{C} 17.5$ mass\% of hydrogen is released from the water to the gaseous form $\left(\mathrm{H}_{2}\right)$ and further temperature growth doesn't affect this 


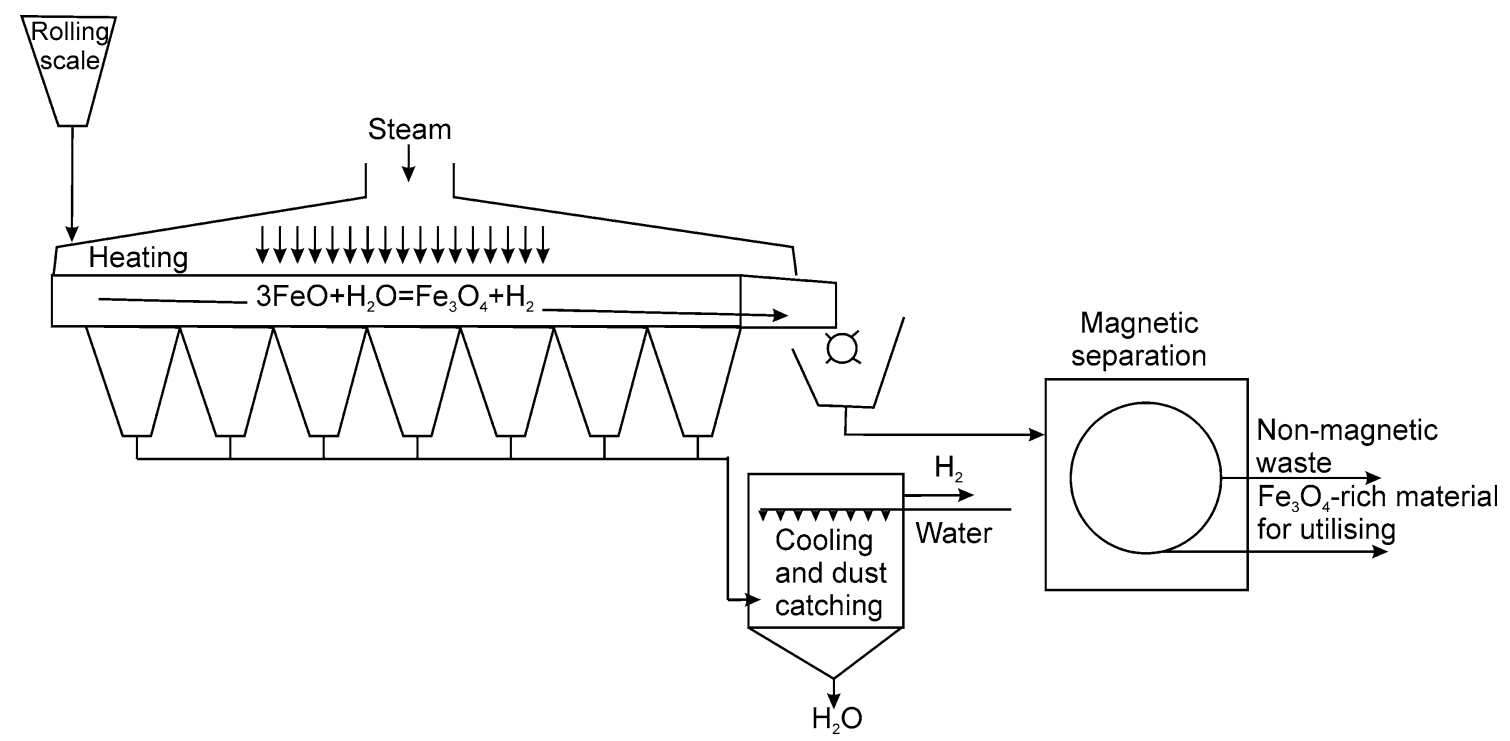

Fig. 5 Water splitting technology scheme based on utilizing the rolling mills scale

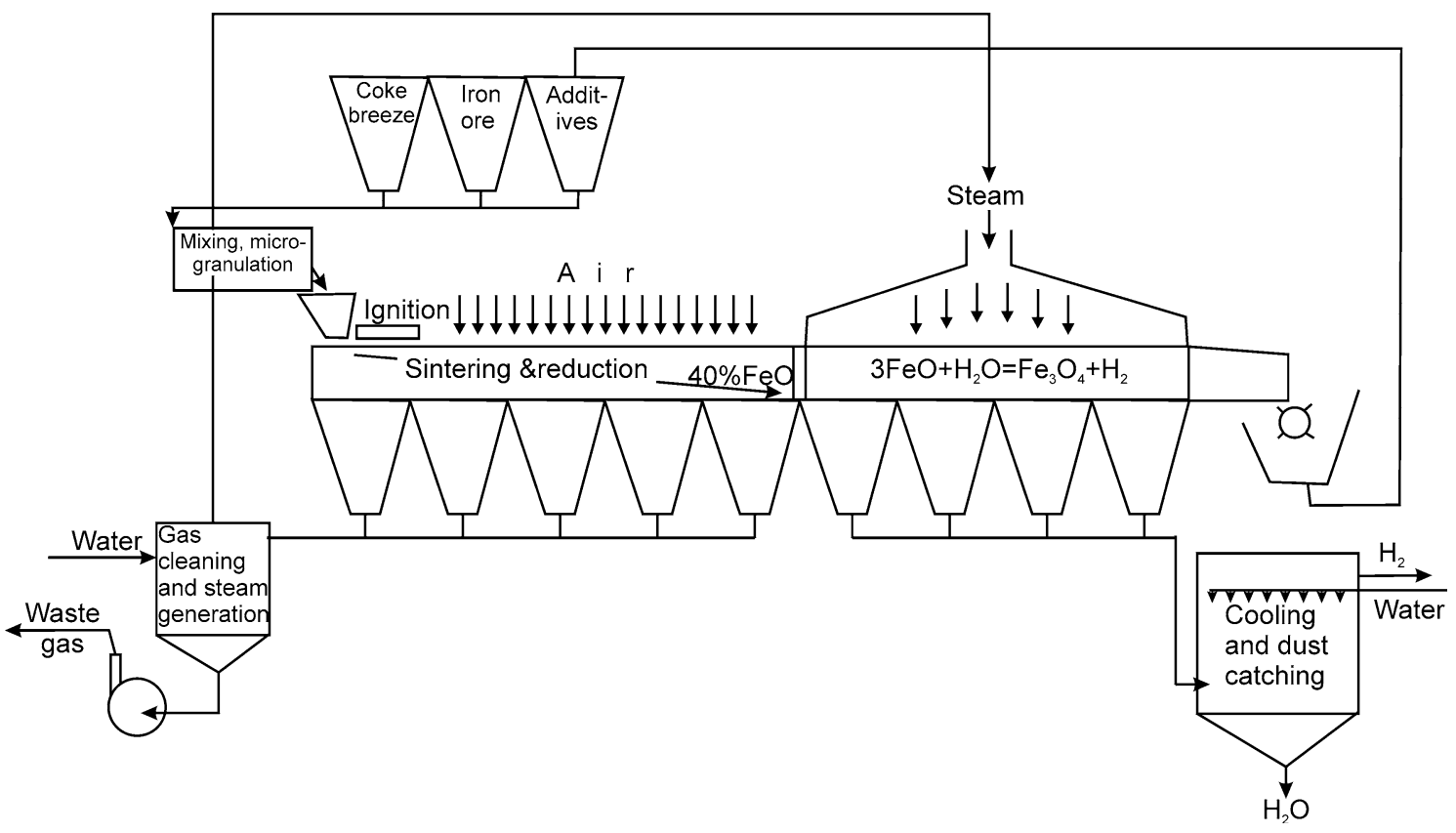

Fig. 6 Water splitting technology scheme based on production of high $\mathrm{FeO}$ sinter with its consequent use for water splitting at the modified sinter plant

figure in the given range. Solid phase content is shown in Fig. 3 and the results obtained allow assuming that in addition to reaction (3), the following process may contribute to water splitting:

$2 \mathrm{CaO}+2 \mathrm{FeO}+\mathrm{H}_{2} \mathrm{O}=\mathrm{H}_{2}+\mathrm{Ca}_{2} \mathrm{Fe}_{2} \mathrm{O}_{5}$

When the temperature decreases down to $300{ }^{\circ} \mathrm{C}$, the water partially reacts with calcium oxide to form portlandite and the quantity of hydrogen released drops by nearly 2 mass\% (abs). The results obtained by Factsage modeling are generally consistent with the scheme shown in Fig. 1.

It should be noted that the ferrous phase in the materials listed in Table 1 might be represented with wüstite or with more complex compounds, e.g., ferrous orthosilicate (fayalite, $\mathrm{Fe}_{2} \mathrm{SiO}_{4}$ ). Using HSC Chemistry software, we estimated the free Gibbs energy of the reaction of fayalite with water in the temperature range $200-800{ }^{\circ} \mathrm{C}$ as follows: 
$3 \mathrm{Fe}_{2} \mathrm{SiO}_{4}+\mathrm{H}_{2} \mathrm{O}=\mathrm{Fe}_{3} \mathrm{O}_{4}+3 \mathrm{FeSiO}_{3}+\mathrm{H}_{2}$

$\Delta G^{\circ}=-37,048+10.0 \mathrm{~T} \mathrm{~J} / \mathrm{mol}$

In the abovementioned temperature range, this reaction is thermodynamically favored $\left(\Delta G^{\circ}<0\right)$. Therefore, application of the materials represented in Table 1 for water splitting has a solid background, even if divalent iron determined by chemical analysis belongs to a silicate phase.

\section{Ferroalloy and Aluminum Industry Wastes}

To estimate a potential of the ferroalloy slag to produce hydrogen, calculations were made using HSC Chemistry software for some relevant reactions. The results in Fig. 4 show that thermodynamically $\mathrm{Si}, \mathrm{FeSi}$, and $\mathrm{SiC}$ have a potential for water splitting even at a room temperature.

Application for water splitting of widely available aluminum-bearing wastes is another considerable option. The reaction products are alumina (which could be used in many applications) and hydrogen. The reaction proceeds with strong exothermic effect. Using HSC Chemistry software, we estimated free Gibbs energy of the reaction of water with aluminum as follows:

$2 / 3 \mathrm{Al}+\mathrm{H}_{2} \mathrm{O}(\mathrm{g})=1 / 3 \mathrm{Al}_{2} \mathrm{O}_{3}+\mathrm{H}_{2}(\mathrm{~g})$

$\Delta G^{\circ}=-299,170+53.0 \mathrm{~T} \mathrm{~J} / \mathrm{mol}$

Despite the favorable thermodynamics even at room temperatures, kinetically this reaction does not proceed due to the layer of aluminum oxide formed on the surface preventing water from the contact with Al. However, for the liquid metal (over $660{ }^{\circ} \mathrm{C}$ ) the reaction is possible [21]. In case hot wastes with liquid $\mathrm{Al}$ are used, the technology appears more reasonable: widely available waste, so-called white dross-slag, skimmed from primary aluminum melting furnaces-contains up to $70 \%$ of metallic aluminum [22].

\section{Possible Technological Applications}

Possible technologies where ferrous materials and wastes are used for water splitting were earlier considered [23] and schematically are represented in Figs. 5 and 6. Figure 5 shows the process flow sheet for the water splitting technology with the utilization of rolling mills scale. Water splitting is exothermic; however, the material must be preheated in order to ensure a high reaction rate. Fine scale (below $2 \mathrm{~mm}$ ) from the secondary settling tanks of a rolling mill contains about 10 mass $\%$ of water and 15 mass $\%$ of oil. Degreasing and dewatering are complicated technological tasks hindering utilization of scale [24]. In our case the bound water, at least partly, could be split to hydrogen. One can assume that thermochemical conversion of the oil to volatile hydrocarbons can occur simultaneously with water splitting under the given conditions. In case of utilizing coarser (over $2 \mathrm{~mm}$ ) scale from primary settling tanks of a rolling mill, the problem of oily matter is not essential (oil content is less than $1.5 \%$ ).

Figure 6 shows a process involving production of high $\mathrm{FeO}$ sinter with its consequent use for water splitting at the modified sinter plant. A special kind of sinter with over 30 mass \% of $\mathrm{FeO}$ was produced in small quantities at some steel factories in Ukraine as the material for so-called washing of a blast furnace hearth (a procedure to eliminate coke fines in heterogeneous liquid slag by reaction $\mathrm{FeO}+\mathrm{C}=\mathrm{Fe}+\mathrm{CO}$ in order to increase slag fluidity). A certain amount of carbon dioxide will be emitted when such kind of sinter is produced; however, application of biofuels to substitute coke breeze can mitigate environmental footprint. Processed sinter might be used either in a blast furnace or recycled.

\section{Conclusions}

On-site production of hydrogen at a steelmaking enterprise is very important to bring about novel hydrogen-based ironmaking processes. Substitution of carbonaceous fuels and reductants in ironmaking by hydrogen may reduce $\mathrm{CO}_{2}$ emissions considerably. Iron monoxide as a material with essential potential for thermochemical water splitting is the focus of lots of researchers. The presence of $\mathrm{FeO}$ in essential quantities in some widely available metallurgical products and wastes makes these materials attractive to use as a contact mass for water splitting. Thermodynamic modeling shows that steelmaking slag can be used for this purpose. Rolling mills scale and specially produced high $\mathrm{FeO}$ iron ore sinter are also possible candidates. Wastes of ferroalloy and aluminum industries, such as ferrosilicon slag and "white dross," also have significant capacity for water splitting. Technological schemes for continuous onsite hydrogen production using rolling mills scale and iron ore as a contact mass are proposed.

\section{References}

1. McDowall W, Eames M (2006) Forecasts, scenarios, visions, backcasts and roadmaps to the hydrogen economy: a review of the hydrogen futures literature. Energy Policy 34:1236-1250

2. Sohn HY, Choi ME (2009) A novel green ironmaking technology with greatly reduced $\mathrm{CO}_{2}$ emission and energy consumption. In: Gupta GS, Lollchund MR (eds) International conference on the 
advances in theory of ironmaking and steelmaking. Allied Publishers Pvt. Ltd, Bangalore, pp 9-27

3. IPCC Fourth Assessment Report: Climate Change 2007. 7.12.1 Longer-term mitigation options. https://www.ipcc.ch/publica tions_and_data/ar4/wg3/en/ch7s7-12.html. Accessed 17 Nov 2015

4. Fekete JR, Sowards JW, Amaro RL (2015) Economic impact of applying high strength steels in hydrogen gas pipelines. Int $\mathbf{J}$ Hydrogen Energy 40:10547-10558

5. Le Duigou A, Quéméré M-M, Marion P et al (2013) Hydrogen pathways in France: results of the HyFrance3 project. Energy Policy 62:1562-1569

6. Roeb M, Sattler C, Klüser R et al (2006) Solar hydrogen production by a two-step cycle based on mixed iron oxides. J Sol Energy Eng 128:125-133

7. Steinfeld A (2005) Solar thermochemical production of hydrogen-a review. Sol Energy 78:603-615

8. Charvin P, Abanades S, Flamant G, Lemort F (2007) Two-step water splitting thermochemical cycle based on iron oxide redox pair for solar hydrogen production. Energy 32:1123-1133

9. Ehrensberger K, Frei A, Kuhn P, Oswald HR, Hug P (1995) Comparative experimental investigations of the water-splitting reaction with iron oxide $\mathrm{Fe}_{1-y} \mathrm{O}$ and iron manganese oxides $\left(\mathrm{Fe}_{1-\mathrm{x}} \mathrm{Mn}_{\mathrm{x}}\right)_{1-\mathrm{y}} \mathrm{O}$. Solid State Ionics 78:151-160

10. Thaler M, Hacker V, Anilkumar M et al (2006) Investigation of cycle behaviour of the contact mass in the RESC process for hydrogen production. Int J Hydrogen Energy 31:2025-2031

11. Vargas V, Gilberto L (2007) Development of chemical looping gasification processes for the production of hydrogen from coal. The Ohio State University, Columbus

12. Bleeker MF, Kersten SRA, Veringa HJ (2007) Pure hydrogen from pyrolysis oil using the steam-iron process. Catal Today $127: 278-290$
13. Bogdandy L, Engel H (1971) Reduction of iron ores. Verlag Stahleisen, Dusseldorf

14. T-Raissi A, Block DL (2004) Hydrogen: automotive fuel of the future. IEEE Power Energ Mag 2:40-45

15. Shatokha V, Pinchuk S (2009) Secondary resources of metallurgy. Dnepr-VAL, Dnipropetrovsk

16. http://www.outotec.com/en/Products-services/HSC-Chemistry/. Accessed 1 Sept 2015

17. http://www.factsage.com/. Accessed 1 Sept 2015

18. Matsuura H, Tsukihashi F (2012) Thermodynamic calculation of generation of $\mathrm{H}_{2}$ gas by reaction between $\mathrm{FeO}$ in steelmaking slag and water vapor. ISIJ Int 52:1503-1512

19. Turkdogan ET (1980) Physical chemistry of high temperature technology. Academic Press, New York

20. Kabanov YuA, Stolyarskii O, Agapeev E (2006) Recovering and recycling scrap from dumps containing steelmaking slag. Metallurgist 50:39-41

21. Petrovic J, Thomas G (2008) Reaction of aluminum with water to produce hydrogen-A study of issues related to the use of aluminum for on-board vehicular hydrogen storage. US Department of Energy, Lakewood, CO. https://www1.eere.energy.gov/hydro genandfuelcells/pdfs/aluminium_water_hydrogen.pdf

22. Hwang JY, Huang X, Xu Z (2006) Recovery of metals from aluminium dross and saltcake. J Miner Mater Character Eng 5:47-62

23. Shatokha V. Continuous method to produce hydrogen: Patent No. 95181. C01B 3/02. 11.07.2011 (Ukraine)

24. Shatokha V, Gogenko O, Kripak S (2011) Utilising of the oiled rolling mills scale in iron ore sintering process. Resour Conserv Recycl 55:435-440 